\title{
Menos profissionais, mais sujeitos: formação para a educação popular no Sistema Único de Saúde (SUS)
}

Pedro Afonso Cortez', Marcus Vinícius Rodrigues de Souza²

\section{Resumo}

As dinâmicas sociais atuais demandam pela emergência de um novo paradigma de atuação em saúde, o qual deve revisitar suas concepções fundamentais - as noções de ser humano, saúde e educação - a fim de superar dificuldades existentes no momento presente e traçar novos caminhos. Para isso, é necessário que os envolvidos nesse processo (docentes, discentes e profissionais) abandonem velhos hábitos, pautados na concepção de saúde como ato exclusivo e autoritário das categorias profissionais, com o intuito de recriar as práticas formativas e os modelos de atuação, tornando-se sujeitos implicados em uma postura dialógica, colaborativa, inclusiva e horizontal capaz de interessarse pelas pessoas e por suas realidades e saberes. Afinal, somente a partir de uma mudança profunda nos aspectos basilares das práticas de formação e atuação em saúde será possível superar as lacunas presentes nos dispositivos de atenção do SUS (Sistema Único de Saúde) rumo à educação popular em saúde e ao exercício dialógico, o qual se apresenta como instrumento imprescindível para a transformação concreta desta realidade.

\section{Palavras-chave}

Educação Popular. Educação em Saúde. Educação Profissional em Saúde Pública. Profissional de Saúde. Trabalho.

1. Doutorando em Psicologia na Universidade São Francisco, São Paulo, Brasil. E-mail: cor.afonso@gmail.com.

2. Graduado em Medicina pela Universidade Federal de Minas Gerais, Brasil. E-mail: marcusrodriguessouza@ hotmail.com. 


\title{
Less professional, more human being: training for popular education at Brazilian Unified Health System (SUS)
}

Pedro Afonso Cortez*, Marcus Vinícius Rodrigues de Souza**

\begin{abstract}
The current social dynamics demand a new paradigm of action in health, which must recreate its fundamentals conceptions, the concepts of human being, health and education, in order to overcome existing difficulties in the present moment and trace new paths. For this reason, it is necessary that those involved in this process (teachers, students and professionals) abandon old habits, based on the conception of health as an exclusive and authoritarian act of the professional categories, aiming to recreate the education and practices, making people involved in a dialogical, collaborative, inclusive and horizontal posture, capable of being interested in people, their realities and knowledge. It is perceived that only with a deeply change in the basic aspects of health education and practices, it will be possible to overcome the gaps in the attention devices of the SUS (Brazilian Unified Health System) in the direction of popular health education and dialogical exercise, which is an essential instrument for change this reality.
\end{abstract}

\section{Keywords}

Popular Education. Health Education. Public Health Professional Education. Health Worker. Work.

* PhD student in Psychology, São Francisco University, State of São Paulo, Brazil. E-mail: cor.afonso@gmail.com. * Graduated in Medicine, Federal University of Minas Gerais, State of Minas Gerais, Brazil. E-mail: marcusrodriguessouza@hotmail.com. 


\section{Introdução}

Em tempos próximos de uma revolução paradigmática, em que as práticas e organizações pautadas em um modelo mecanicista de ser humano denunciam sua ineficácia frente às demandas impostas pela realidade social, faz-se necessário repensar a formação dos profissionais que atuarão nos dispositivos do Sistema Único de Saúde (SUS), a fim de prepará-los para a ruptura do atual paradigma e facilitar a transição para essa nova compreensão de funcionamento social (OLIVEIRA, 2005). Entretanto, diferentemente de outros momentos históricos, em que essas rupturas sinalizaram uma possibilidade de reforma, nota-se, atualmente, uma movimentação social que dificilmente se dará apenas no nível de adequação e reformas dos dispositivos sociais (PAIVA; TEIXEIRA, 2014).

As noções estabelecidas na 8aㅡ Conferência Nacional de Saúde fornecem pistas sobre os caminhos a serem seguidos nessa transformação: a organização social da produção influencia a relação entre os sujeitos, o que, por si, implica na atuação conjunta e colaborativa entre atores sociais para definir novas formas de organização social (BRASIL, 1986). Assim, a conjuntura atual solicita aos profissionais que eles abandonem completamente suas vestes brancas e seus ideais de suposta neutralidade e assumam uma postura de sujeitos, imersos no terreno dialógico da intersubjetividade em suas atuações no SUS, como uma via para a construção de proposições transformacionais capazes de responder às demandas do momento atual (AMENDOLA, 2014). Dessa forma, muito mais do que uma reavaliação das técnicas empregadas pelos profissionais em suas áreas, caberá aos sujeitos imersos na construção de práticas em educação popular e saúde reescreverem concepções fundamentais do seu trabalho, a saber: as noções de ser humano, saúde e educação.

Nesse ponto, é importante uma ressalva para esclarecimento, pois, notavelmente, os anos de formação profissional podem servir para aprimorar o trabalho daqueles que se dedicam à área de saúde (MITRE et al., 2008). No entanto, a crítica deste ensaio sobre a formação destina-se especificamente à forma como costumeiramente são mediadas as relações de ensino- aprendizagem e seus impactos na compreensão de mundo dos indivíduos em formação. Em vez de expandir os horizontes dos educandos, a formação profissional com predominância endógena e tecnicista valida os princípios de exclusão que permeiam a dinâmica de seleção dos eleitos para o exercício do processo curativo e age como um rolo compressor frente aos demais saberes. Sem as certificações das bases de dados, níveis de evidência empírica e padrões de tratamento comuns aos saberes acadêmicos e profissionais o saber cotidiano das classes populares é invalidado antes que possa ressonar concretamente por meio das falas da população (LEITE; LIMA, 2015). Nas seções seguintes essa dinâmicaéaprofundada eexplorada em detalhes.

\section{A dimensão da saúde: relações de poder e misticismo}

Antes de avançar nas discussões acerca da formação profissional, é preciso, previamente, estabelecer uma breve contextualização sobre o campo, com intuito de dimensionar adequadamente os pressupostos a que este texto se refere. Nesse sentido, compreendese que as práticas de saúde, no decorrer da história, prevaleceram como um privilégio de poucos que eram capazes de exercê-las (BRASIL, 2014). Dos modelos sociais tribais às sociedades contemporâneas, fazer saúde sempre apresentou relevância, seja por meio de aspectos totêmicos até as intervenções mais recentes das 
ciências da saúde. Como exemplo do exercício de práticas curativas nota-se na história do homem diversas manifestações, tais como: curas xamânicas (LÉVI-STRAUS, 1975), já bastante conhecidas e investigadas por antropólogos; discursos de poderes e graças divinas atribuídas às igrejas (CEQUEIRA-SANTOS; KOLLER; PEREIRA, 2004), especialmente durante a época medieval, em que a Igreja alcançou seu ápice de influência na estruturação social e, de forma mais recente, aos profissionais da área de saúde, os quais são investidos de um saber formal e técnico, regrado por longos anos nas cadeiras e corredores dos cursos e hospitais universitários (PEREIRA; ALMEIDA, 2005).

Enfatizando-se nessa dinâmica das relações entre os homens e a habilidade de curar, observa-se que, ao longo do tempo, o exercício do curador sempre foi marcado por um substrato de poder e misticismo que o diferencia dos demais. Há uma dicotomia entre os saberes formais de saúde dos profissionais dessa área e da população geral, erroneamente nomeada como "leiga" (SOUZA; WEGNER; GORINI, 2007). Dessa forma, percebe-se que o privilégio proporcionado pelos saberes profissionais em detrimento ao "desconhecimento" daqueles que demandam por atenção à saúde demarcou, ao longo da história, uma secção em relação aos posicionamentos sociais nesse campo. Essa dicotomia entre agentes ativos e passivos da relação de cura é revelada cotidianamente por meio de nossos hábitos, os quais podem ser referenciados por nossas experiências em aspectos que constituem nossa realidade (PEREIRA; ALMEIDA, 2005).

Partindo da linguagem, para compreender essa relação dicotômica entre os profissionais de saúde e a população geral, observa-se que o termo "paciente", utilizado de forma recorrente em contextos de saúde, reforça formas excludentes de interação. Aquele que se submete aos saberes formais dos profissionais da saúde normalmente é nomeado como "paciente". Ao paciente, com ou sem paciência, resta aguardar na passividade pelos cuidados que serão determinados pelo único agente ativo da relação: o profissional de saúde (KLUG, 2002). De forma semelhante aos modelos curativos totêmicos, o sujeito investido da prática curativa age com suposta superioridade profissional, como detentor dos saberes, práticas e conhecimentos acerca das formas ótimas de conservação e existência do sujeito paciente que espera pela solução. Outras representações da linguagem, advindas de contextos mais recentes, também potencializam as práticas dicotômicas e verticalizadas, ampliando ainda mais a distância relacional entre paciente e seus senhores por meio de vocativos como: mestres, doutores e especialistas em geral (CAPRARA, 2004). Dirigindo-se a atenção para as relações entre doutores e "pacientes", observa-se, na noção de saúde, o principal catalisador das relações sociais. Estar saudável é sinônimo de inclusão social, possibilidade de trabalho, pertencimento e consumo. Em última instância, estar saudável atesta às possiblidades de vida dos sujeitos (CANGUILHEM, 1986). Dessa forma, é visível que, no contexto atual, a saúde é, antes de tudo, um estado de poder (PEREIRA, 2004). Ela legitima o quanto as pessoas conseguem lidar com suas realidades e reafirma suas identidades como atores sociais. Em um espectro ideal, a saúde destina-se a todos, sejam eles profissionais dessa área ou pertencentes aos demais setores da população. No entanto, na prática, ela é mediada no processo de saúde-doença por uma lacuna abissal: os supostos saberes dos profissionais de saúde e a desqualificação das formas de viver, agir e autocuidado dos "pacientes" e de outros sujeitos, a qual se origina, em grande parte, ao longo das trilhas formativas dos profissionais de saúde. 


\section{0 percurso pessoal: as trilhas formativas dos sujeitos}

Para pensar as trilhas formativas dos sujeitos em saúde é necessário partir da dimensão do pertencimento: é apriorístico estar saudável, "normal" em oposição ao "patológico" como condição desejável para adentrar o círculo daqueles capazes de exercer o ato curativo (CANGUILHEM, 1986). Em nossa realidade, os círculos de formação profissional para saúde emergem, em grande parte, nos dispositivos sociais pautados na seleção por meio da exclusão social (VIGINHESKI et al., 2004) os quais, ao agirem dessa forma, iniciam o processo de segregação entre profissional e sujeito, a partir de uma mensagem sutil: a saúde é para poucos e seus aspectos superiores são ainda mais exclusivos a uma casta restrita de indivíduos.

O impacto dessa mensagem ao longo das trilhas formativas é verificável ao se observar os meios que selecionam e designam as pessoas que receberão a formação para trabalhar nesse campo. De forma geral, as categorias profissionais com maior influência técnica residem no âmbito da universidade, a qual demanda regime integral para preparação e formação desses profissionais. Seguem, de forma hierarquicamente ilusória, mas com implicações concretas na prática, o escalonamento depreciativo da equipe de trabalho, abrangendo desde as formações de nível superior (SCHWARTZMAN, 1985) e findando nas atuações exercidas por técnicos (ALVES, 2013) e agentes comunitários, cuja existência se apresenta como elemento de resistência em meio ao contexto de valorização excessiva dos saberes exclusivamente técnicosacadêmicos (ZAMBENEDETTI, 2014).

Do ponto de vista da formação universitária, a necessidade de dedicação integral por si só acrescenta aos apriorísticos "normal" e "saudável" outro elemento necessário para aquele que deseja atuar em saúde: é preciso ter classe, compreendendo-se classe como a estratificação social capaz de financiar a subsistência do sujeito em formação em tempo integral, sem que seja necessário o envolvimento daquele indivíduo no sustento familiar (BORGES, 2005). Em relação a essa dinâmica de exclusão classista, tem-se avançado nos últimos anos nas políticas de inclusão das classes populares e minorias nas universidades públicas (ALVES, 2002). Contudo, sem adequações no regime de dedicação aos cursos, mantém-se a relação de exclusão frente às classes populares, que demandam tempo para o trabalho, como uma tentativa de contribuir com o orçamento para a subsistência familiar, a despeito das iniciativas de assistência e financiamento estudantil que tem se mostrado insuficientes e restritas para alterar esse contexto (VASCONCELOS, 2010).

É notável que, apesar da existência de ações assistenciais capazes de subsidiar ao discente transporte, alimentaçãoe, em casos mais raros, moradia, esse sujeito não se desvincula de sua realidade ao adentrar a universidade: permanece membro de uma família e de suas compreensões e demandas específicas. Nesse sentido, talvez esteja nesse ponto o grande equívoco das políticas de assistência estudantil: considerar apenas os elementos necessários para manter o discente na universidade, ao passo que, sem abarcá-lo como sujeito, a partir da apreensão de seu contexto de origem e vinculação familiar, dificilmente será possível romper com o ciclo de exclusão das classes populares nas trilhas formativas.

Em última instância, as trilhas formativas dos sujeitos perpassam a origem histórica e contexto de constituição dialógica, os quais se subsidiam primordialmente nos vínculos comunitários e familiares (LEVI-STRAUSS, 2003). Dessa forma, para manter a inclusão como uma prática efetiva é preciso que as políticas assistenciais estudantis também almejem fortalecer o contexto originário do estudante, especificamente os vínculos mais próximos. 


\section{0 caminho profissional: as particularidades da técnica}

Estabelecida a compreensão de sujeito que perpassa as trilhas formativas e suas especificidades contextuais, faz-se mister postular a diferenciação entre duas categorias: sujeitos e profissionais. Essa distinção é fundamental para compreender a dimensão da técnica e o caminho profissionalizante (LEÃO, 2001). Em uma acepção comum, o sujeito está voltado para a realidade em um sentido de relação implicada e dialógica, questionando-se acerca de sua própria existência, do seu lugar do mundo e do seu papel na interação com os demais: é o sujeito vivente em constante experiência (FREIRE, 1979). Por sua vez, a categoria profissional direciona-se à apropriação da técnica e aplicação dela ao objeto de interesse. Nessa condição, o sujeito é capaz de interagir, relacionar-se e assumir uma postura compreensiva e instigadora diante da realidade, tal como preconizado pelos princípios de educação popular em saúde, ao passo que o profissional se volta para a realização da tarefa, como um objetivo em si mesmo. Essas categorias são fundamentais, pois sinalizam como cada pessoa compreenderá sua realidade e realizará suas ações enquanto ator social. Do ponto de vista do sujeito, esperam-se papeis de protagonismo e recriação da realidade (SEGRE; FERRAZ, 1997). Em contrapartida, os modelos mais fechados, inerentes à categoria profissional, tendem a optar pelo formalismo, normatização e reprodução do paradigma vigente, ainda que alguns de seus pressupostos se demonstrem insuficientes. Nesses termos, a ação e a implicação são elementares aos sujeitos, emergem no diálogo, nas trocas abertas e na construção de saberes mútuos, ao passo que a técnica nasce de trocas fechadas em codificações e jargões específicos, acessíveis somente aos sujeitos de suposto saber (COTTA; FERRARI, 2016).
Por essa razão, é possível perceber o quanto a técnica é reforçada e valorizada nas universidades por diferentes classes profissionais (FREIRE, 1987). As diversas classes profissionais investem esforços no sentido de apropriar para si procedimentos, técnicas, métodos e ações exclusivas (FURTADO; CAMPOS, 2005). Nessa perspectiva, foca-se na superioridade e na manutenção do status quo de poder e dominação classista, em vez da finalidade da prática em si: o ato curativo e suas implicações (KOMATSU, 2002). Assim, o indivíduo em formação vai perdendo de vista aspectos que norteiam seu vínculo intersubjetivo - a finalidade da ação, o lugar da interação e troca com o mundo - em favor da soberba e do pertencimento à casta profissional de suposto saber que se reproduz na linha do tempo (NOGUEIRA, 2009). Morre o sujeito, dá-se à luz ao profissional, como aquele detentor dos saberes e práticas de saúde, devido sua condição diferenciada, obtida por meio de anos dedicados à formação e à pesquisa que, aparentemente, o habilita para possuir exclusividade sobre o catalisador das relações de pertencimento: a prática de saúde.

Em grande parte, as primeiras experiências de silenciamento entre profissional de suposto saber e paciente acontecem longe dos consultórios e unidades de saúde. O profissional que hoje silencia o saber popular é aquele que outrora foi silenciado em sala de aula (FREIRE; 1987). Dessa forma, é fundamental reconhecer a docência como um lugar capaz de fundamentar duplamente a dimensão do saber, a rigor: profissional - relativo ao saber técnico - e pessoal - próprio do saber dialógico, construtivo e emancipatório (SANTOS, 2010). Por essa razão, é preciso entender que as técnicas e suas aplicações nos caminhos profissionais refletem as trilhas formativas dos sujeitos, as quais se sustentam, em grande parte, a partir da potência daqueles que nomeiam os caminhos na estrada profissionalizante: os educadores (FREIRE, 2015). Só se pode "ser 
mais" (MELO; NOGUEIRA, 2012) quando os "inculcamentos" (FREIRE, 2014) técnicos podem ser perpassados pela brisa dos diálogos, capazes de transformar o silenciamento em preceitos de educação para a transformação das dinâmicas de formação e trabalho em saúde no SUS.

\section{Perspectivas e desafios de atuação no SUS: a (des)construção do profissional e a emersão do sujeito}

Partindo das noções apresentadas até então, se torna possível vislumbrar possibilidades sobre o desafio de construir trilhas formativas e sujeitos capazes de agregar ao SUS os princípios da educação popular em saúde. Primeiramente, faz-se preciso apreender o quanto a organização do SUS, ainda que preconizada por diretrizes de inclusão e participação social, encontra limitações para seu efetivo exercício (VASCONCELOS, 2005), o que implica em atenção precária à saúde em diversos pontos da rede, principalmente nas regiões Norte e Nordeste, no interior do país e nas porções mais pobres das grandes cidades (COELHO, 2007). Esse retrato é resquício da mentalidade exclusivamente técnica e profissional predominante ao longo dos anos de formação em saúde, cuja finalidade é exercer a prática como um princípio em si mesmo, sem considerações com o mundo e as demandas acerca da realidade do país, especificamente da rede SUS.

Como forma de alterar essa realidade, com o intuito de abranger os princípios norteadores do SUS, a fim de garantir a integralidade e a universalidade da assistência e promoção à saúde, é preciso sensibilizar e conscientizar os educandos por meio de formação crítica e contextualizada, estabelecendo a noção de que a saúde é um importante instrumento tanto para a dominação, quanto para o empoderamento e a inclusão social das pessoas (KRUSCHEWSKY, 2008). A partir dessa conscientização, existe a possibilidade de implicação do profissional, emergindo o recurso dialógico necessário para a efetivação dos preceitos de educação popular em saúde no SUS: a reinvenção dos conceitos de ser humano, saúde e educação.

Aliás, é importante destacar que, se da técnica nasce o profissional e morre o sujeito, da implicação e preocupação com os efeitos concretos de sua atuação, extinguese o profissional e emerge o sujeito capaz de fazer da sua técnica um meio para mediação e transformação do contexto que se dispõe em interação na rede SUS (GUIMARÃ̃ES; MACEDO, 2009). Nessa dinâmica iniciase, então, a desconstrução da categoria solipsista e silenciadora de profissional rumo ao reconhecimento, por parte do indivíduo, da sua noção de sujeito, de que sua atuação deve buscar um sentido de construção coletiva visando à promoção de saúde para todos. Essa postura implica em abandonar o exercício da técnica por si mesma, almejando um ideal social capaz de transformar a saúde como um meio favorável à horizontalidade e a maior participação e controle social (BARBOSA, 2015).

Da horizontalidade, abandona-se a falácia da suposta verticalidade e hierarquia entre os conhecimentos, práticas e profissionais, emergindo a potência dialógica de que as pessoas e suas realidades são mais importantes do que os diplomas e as certificações. Somente os sujeitos em interação são capazes de agregar os diversos saberes, que constroem e colaboram na concepção de saúde e cuidado ótimo de suas necessidades (FALKENBERG et al., 2014). Por meio dessa postura interativa, a noção de ser humano expande-se para um projeto de educação e saúde como atividade compartilhada e negociada, cuja predominância formal e exclusiva é rompida em nome de relações próximas e empoderadoras, capazes de responder às mudanças paradigmáticas necessárias para superar as insuficiências 
daqueles que insistem em um modelo de saúde sectarista inadequado às demandas da rede SUS (ANJOS, 2010).

\section{Considerações finais}

Por fim, se nas mudanças nas concepções de ser humano, saúde e educação alicerçamse, do ponto de vista conceitual, os princípios para efetivar a educação popular em saúde no SUS, na perspectiva prática essas alterações são desencadeadas por modificações pontuais que, somadas, são capazes de delinear, em longo prazo, políticas mais abrangentes e integradoras sobre o tema. Essas práticas acontecem por meio da docência, que repensa seu lugar na relação com o educando; do profissional, o qual abre mão desta categoria para fazer trocas e construções com o mundo; ou, ainda, por meio das políticas inclusivas, que, ao reparar as injustiças e exclusões permeadas ao longo da história (PIOVESAN, 2005), trazem para os ciclos acadêmicos e formais as classes populares e suas marcas impressas nas experiências cotidianas.

Registra-se, por meio deste texto, a tentativa dos autores de dar voz ao silêncio de outrora e visibilidade às marcas do que representa perpassar por cursos da área de saúde, tendo como origem pessoal as classes populares. Possivelmente, melhor do que as palavras dos autores, sejam os escritos de Paulo Freire para abarcar a complexidade do fenômeno analisado: qualquer ato de libertação resulta sempre em dualidade (FREIRE, 1987).

No contexto de formação vivenciado pelos propositores desse escrito, tendo como premissa a busca pela efetivação da educação popular em saúde no SUS, encerra-se este ensaio com um relato autobiográfico que totaliza a experiência dos autores nesse processo dual: um constante vir a ser entre tornar-se profissional sem perder de vista a dimensão de sujeito que nos constitui. Afinal, a efetivação da saúde como direito fundamental só existe quando podemos reconhecer nossas necessidades - e as dos outros - por meio do diálogo, sendo esse o caminho para romper com a supremacia de uma prática sectarista, pautada em "segredos macrobiológicos", rumo ao modelo de saúde e formação colaborativo, vislumbrado por meio da $8^{\underline{a}}$ Conferência Nacional de Saúde.

\section{Referências}

ALVES, J. M. A assistência estudantil no âmbito da política de educação superior pública. Serviço Social \& Sociedade, São Paulo, v. 5, n. 1, p. 1-8, 2002.

ALVES, L. A. M. Ensino técnico: uma necessidade ou uma falácia? Notas para a compreensão da filosofia do ensino técnico em Portugal e no Brasil. História da Educação, Portugal, v. 17, n. 41, p. 103-122, 2013. doi: https://doi.org/10.1590/S2236-34592013000300007.

AMENDOLA, M. F. Formação em psicologia, demandas sociais contemporâneas e ética: uma perspectiva. Psicologia: Ciência e Profissão, Brasília, v. 34, n. 4, p. 971-983, 2014. doi: https://doi. org/10.1590/1982-370001762013.

ANJOS, R. M. P. et al. "Vivendo o SUS": uma experiência prática no cenário da atenção básica. Revista Brasileira de Educação Médica, Rio de Janeiro, v. 34, n. 1, p. 172-183, 2010.

BARBOSA, A. M. et al. Fórum Permanente de Educação Popular em Saúde: construindo estratégias 
de diálogos e participação popular. Revista de APS, Juiz de Fora, v. 18, n. 4, p. 554-559, 2015.

BORGES, J. L. G.; CARNIELLI, B. L. Educação e estratificação social no acesso à universidade pública. Cadernos de Pesquisa, São Paulo, v. 35, n. 124, p. 113-139, 2005. doi: https://doi. org/10.1590/S0100-15742005000100007.

BRASIL. Ministério do Desenvolvimento Social e Combate à Fome. O Brasil sem Miséria. Brasília: MDS, 2014. 725 p.

BRASIL, Ministério da Saúde. 8ª Conferência Nacional de Saúde: Relatório. Brasília: MS, 1986. $29 \mathrm{p}$.

CANGUILHEM, G. Lo normal y lo patológico. Argentina: Siglo XXI, 1986. 242 p.

CAPRARA, A.; RODRIGUES, J. A relação assimétrica médico-paciente: repensando o vínculo terapêutico. Ciência \& Saúde Coletiva, Rio de Janeiro, v. 9, n. 1, p. 139-146, 2004.

CERQUEIRA-SANTOS, E.; KOLLER, S. H.; PEREIRA, M. T. L. N. Religião, saúde e cura: um estudo entre neopentecostais. Psicologia: Ciência e Profissão, Brasília, v. 24, n. 3, p. 82-91, 2004. doi: https://doi.org/10.1590/S1414-98932004000300011.

COELHO, I. B. Os impasses do SUS. Ciência e Saúde Coletiva, Rio de Janeiro, v. 12, n. 2, p. 309311, 2007.

COTTA, M. S.; FERRARI, I. F. Interface entre um método de tratamento psíquico e a cultura. Cadernos CESPUC de Pesquisa, Belo Horizonte, n. 28, p. 168-175, 2016.

FALKENBERG, M. B. et al. Educação em saúde e educação na saúde: conceitos e implicações para a saúde coletiva. Ciência \& Saúde Coletiva, Rio de Janeiro, v. 19, n. 3, p. 847-852, 2014.

FREIRE, P. Conscientização: teoria e prática da libertação: uma introdução ao pensamento de Paulo Freire. São Paulo: Cortez \& Morales, 1979.

Educação como prática da liberdade. Rio de Janeiro: Paz e Terra, 2014. 149 p.

Pedagogia do oprimido. Rio de Janeiro: Paz e Terra, v. 3, 1987. 253 p.

192 p.

Professora, sim; tia, não: cartas a quem ousa ensinar. Rio de Janeiro: Paz e Terra, 2015.

FURTADO, J. P.; CAMPOS, R. O. A transposição das políticas de saúde mental no Brasil para a prática nos novos serviços. Revista Latino-americana de Psicopatologia Fundamental, São Paulo, v. 8, n. 1, p. 109-22, 2005. doi: https://doi.org/10.1590/1415-47142005001011.

KLUG, W. A. O que o paciente espera. In: ISMAEL, J. C. O médico e o paciente: breve história de uma relação delicada. São Paulo: MG Editores, 2002. p. 21-22.

KOMATSU, R. S. Educação médica: responsabilidade de quem? Em busca dos sujeitos da educação do novo século. Revista Brasileira de Educação Médica, Rio de Janeiro, v. 26, n. 1, p. 55-61, 2002.

KRUSCHEWSKY, J. E; KRUSCHEWSKY, M. E.; CARDOSO, J. P. Experiências pedagógicas de educação popular em saúde: a pedagogia tradicional versus a problematizadora. Revista Saúde. 
Com., Itapetinga, v. 4, n. 2, p. 160-175, 2008.

LEÃO, I. B. Como os homens podem ser competentes, se educados para serem hábeis, quando as habilidades já não existem? Uma "nota" da psicologia sobre a educação profissional proposta pelo PLANFOR/BR. Intermeio, Campo Grande, v. 7, n. 14, p. 42-64, 2001.

LEITE, J. C.; LIMA, L. G. S. Cuidado em saúde: sujeito, saberes e a opção decolonial. Revista Internacional de Folkcomunicação, Ponta Grossa, v. 13, n. 29, p. 50-62, 2015. doi: https://doi. org/10.20423/1807-4960/rif.v13n29p50-62.

LÉVI-STRAUS, C. O feiticeiro e sua magia. In: Antropologia Estrutural I. Rio de Janeiro: Tempo Brasileiro, 1975, p. 193-213.

As estruturas elementares do parentesco. Petrópolis, Rio de Janeiro: Vozes, 2003. 540 p.

MELO, E. S.; NOGUEIRA, M. O. A humanização do ser humano em Paulo Freire: a busca do "ser mais". Formação@ Docente, Belo Horizonte, v. 3, n. 1, p. 15-30, 2012.

MITRE, S. M. et al. Metodologias ativas de ensino-aprendizagem na formação profissional em saúde: debates atuais. Ciência \& Saúde Coletiva, Rio de Janeiro, v. 13, n. 2, p. 2133-2144, 2008.

NASCIMENTO, P. G.; GUIMARÃES, T. M. M. A relação médico-paciente e seus aspectos psicodinâmicos. Revista Bioética, Brasília, v. 11, n. 1, p. 101-114, 2009.

NOGUEIRA, M. I. As mudanças na educação médica brasileira em perspectiva: reflexões sobre a emergência de um novo estilo de pensamento. Revista Brasileira de Educação Médica, Rio de Janeiro, v. 33, n. 2, p. 262-270, 2009.

OLIVEIRA, D. L. L. C. A “ nova” saúde pública e a promoção da saúde via educação: entre a tradição e a inovação. Revista Latino-americana de Enfermagem, Ribeirão Preto, v. 13, n. 3, p. 423-431, 2005. doi: https://doi.org/10.1590/S0104-11692005000300018.

PAIVA, C. H. A.; TEIXEIRA, L. A. Reforma sanitária e a criação do Sistema Único de Saúde: notas sobre contextos e autores. História, Ciências, Saúde-Manguinhos, Rio de Janeiro, v. 21, n. 1, p. 15-36,2014.

PEREIRA, O. P.; ALMEIDA, T. M. C. A formação médica segundo uma pedagogia de resistência. Interface: Comunicação, Saúde, Educação, Botucatu, v. 9, n. 16, p. 69-79, 2005.

PEREIRA, W. R. Poder, violência e dominação simbólicas nos serviços públicos de saúde. Texto \& Contexto: Enfermagem, Florianópolis, v. 13, p. 391-400, 2004.

PIOVESAN, F. Ações afirmativas da perspectiva dos direitos humanos. Cadernos de Pesquisa, São Paulo, v. 35, n. 124, p. 43-55, 2005. doi: https://doi.org/10.1590/S0100-15742005000100004.

ROCHA, B. V. et al. Relação médico-paciente. Revista do Médico Residente, Curitiba, v. 13, n. 2, p. 114-118, 2011.

SANTOS, B. S. A universidade no século XXI: para uma reforma democrática e emancipatória da universidade. 3. ed. São Paulo: Cortez, 2010. 116 p. 
SCHERER, M. D. A.; PIRES, D.; SCHWARTZ, Y. Trabalho coletivo: um desafio para a gestão em saúde. Revista de Saúde Pública, São Paulo, v. 43, n.4, p. 721-725, 2009. doi: https://doi. org/10.1590/S0034-89102009000400020.

SCHWARTZMAN, S. O que fazer com a Universidade? In: BORI, C. M. et al. (Orgs.). Universidade brasileira: organização e problemas. São Paulo: SBPC, 1985. p. 229-234. (Suplemento Especial de Ciência e Cultura).

SEGRE, M.; FERRAZ, F. C. O conceito de saúde. Revista de Saúde Pública, São Paulo, v. 31, n. 5, p. 538-542, 1997. doi: https://doi.org/10.1590/S0034-89101997000600016.

SOUZA, L. M.; WEGNER, W.; GORINI, M. I. P. C. Educação em saúde: uma estratégia de cuidado ao cuidador leigo. Revista Latino-americana de Enfermagem, Ribeirão Preto, v. 15, n. 2, p. 337 343, 2007. doi: https://doi.org/10.1590/S0104-11692007000200022.

VASCONCELOS, C. M. Uma análise entrelaçada sobre os paradoxos da mudança no SUS. 2005. 251 f. Tese (Doutorado em Saúde Coletiva). Universidade Estadual de Campinas, Campinas, 2005.

VASCONCELOS, N. B. Programa Nacional de Assistência Estudantil: uma análise da evolução da assistência estudantil ao longo da história da educação superior no Brasil. Ensino em Re-Vista, Uberlândia, v. 17, n. 2, p. 599-616, 2010.

VIGINHESKI, L. V. M. et al. Vestibular: o desafio da inclusão na exclusão. Ciência \& Educação, Bauru, v. 5, n. 2, p. 38-42, 2004.

ZAMBENEDETTI, G. et al. Psicologia e análise institucional: contribuições para os processos formativos dos agentes comunitários de saúde. Psicologia: Ciência e Profissão, Brasília, v. 34, n. 3 , p. 690-703, 2014. doi: https://doi.org/10.1590/1982-3703001302013.

Submetido em 20 de fevereiro de 2017.

Aprovado em 2 de abril de 2017. 